\section{Prevent misuse of eco-compensation}

China is piloting a new type of ecological compensation scheme in which developers pay to offset environmental damage. We are concerned that this policy could have the opposite effect.

Ecological compensation by developers in northwest Europe must restore natural habitats and resources to maintain ecological functions and services (see E. Wolanski and M. Elliott Estuarine Ecohydrology; Elsevier, 2015). By contrast, ecological restoration is not a priority under China's pilot scheme. Developers may choose to pay government authorities directly rather than opting to restore ecosystems, which is generally more expensive, time-consuming and scientifically demanding.

We are concerned that the payment system could be misused by treating it as 'buying' the right to inflict further damage. We therefore urge the government to develop an ecological compensation policy that is conditional on ecological restoration.

Qinhua Fang Xiamen University, China.

Michael Elliott University of Hull, UK.

qhfang@xmu.edu.cn

\section{Speed publication of self-corrections}

Kudos to Daniele Fanelli for suggesting that authors deserve credit for retracting papers that result from honest errors (Nature 531, 415; 2016). Journal editors and co-authors can be helpful, collaborative and efficient - as they were in the case of two papers I retracted in 2013 (see go.nature.com/ jp9meh). However, this is not always the case.

The editorial process can often be lengthy. After waiting for more than two years for the formal resolution of a potential notice of error for another, related paper, I decided to use PubMed Commons to alert the scientific community (see go.nature.com/jzpjfk).

Authors themselves can be uncertain about how to correct the scientific record promptly, even when they suspect errors. They might have moved on to new projects, key contributors may have left the lab, or perhaps they are reluctant to use precious funds to repeat old experiments. Maybe the materials that are needed to repeat the experiments are no longer available, or the authors are slow to reach a consensus on appropriate action.

In my view, these problems could be rectified by standard guidelines for researchers, editors and databases on how to handle self-reported amendments. Terms that are more nuanced than 'correction' or 'retraction' - such as 'notice of concern' or 'error alert' - could be used for situations that are less clear-cut. Pamela Ronald University of California, Davis, USA. pcronald@ucdavis.edu

\section{EU list should add potential invasives}

To be effective, the list of invasive alien species that are targeted for action under the latest European Union regulation needs to focus on preventing new species from entering Europe, and to impede the spread of those that currently have a limited distribution (see also J. Pergl et al. Nature 531, 173; 2016, and F. Santarém et al. Nature 532, 177; 2016).

To be listed under the regulation, species must have been fully risk-assessed. However, existing assessments are mainly for species that are already widespread. All but 2 of the 37 invasive species on the $2015 \mathrm{EU}$ list (see go.nature.com/gigftz) are present in Europe, and 14 are widely dispersed. Of the 95 species that have been identified as potentially invasive (see go.nature.com/avgfb1), only the South American raccoon (Nasua nasua) is on the present list.

In our view, post-invasion management is likely to be more successful and cost-effective if the legislation's 'black list' were to focus on potential future invaders as well as on mitigating the impacts of existing invaders. Maiju Lehtiniemi ${ }^{\star}$ Finnish Environment Institute, Helsinki, Finland. maiju.lehtiniemi@ymparisto.fi ${ }^{*}$ On behalf of 4 correspondents (see go.nature.com/jbvxnz for full list).

\section{Nicaragua Canal may not benefit shipping}

We contend that the benefits of the proposed Nicaragua Canal cannot justify the irreversible damage that it would cause to the environment (see A. Meyer and J. A. Huete-Pérez Nature 506, 287-289; 2014).

With the Panama Canal's widening due to be completed in the next month or so, the argument that the Nicaragua Canal could better accommodate large container ships is no longer valid. Such vessels are of marginal significance to transPacific shipping anyway, owing to insufficient freight demand and port limitations. And as manufacturing bases shift from China to south and southeast Asia, more of Asia's outbound container ships use the Suez Canal to reach eastern US ports.

The Nicaragua Canal would be much longer than the Panama Canal, and so would probably incur higher fees for bulk carriers, tankers and other vessels. On routes that link North America with Asia, large vessels already tend to sail around South Africa's Cape of Good Hope to avoid canal fees.

The Nicaraguan government has also underestimated the safety risks. The country experiences frequent earthquakes, hurricanes and volcanic eruptions - which led the United States to select Panama over Nicaragua for a transoceanic canal in the first place.
Jihong Chen Shanghai Maritime University, China.

Xiang Liu Rutgers University, Piscataway, New Jersey, USA. jhchen@shmtu.edu.cn

\section{Clean up the air in Kathmandu}

The rebuilding and development of Kathmandu's infrastructure after last year's earthquake in Nepal offer a unique opportunity to improve the city's air quality. According to one ranking, Kathmandu is currently Asia's most polluted city (see go.nature. com/csbt1c).

Kathmandu's air pollution is increasing uncontrollably owing to a lack of environmental legislation in the face of haphazard expansion. The number of vehicles has tripled over the past ten years, and toxic particulates are now "far above" World Health Organization guidelines (A. Gurung and M. L. Bell J. Expo. Sci. Environ. Epidemiol. 22, 235-242; 2012). Unregulated industrial activity, dust from the congested road system and open burning of solid waste all add to the pollution. Moreover, Kathmandu lies in a valley, the topography of which causes temperature inversions that trap this polluted air making it barely breathable on occasions.

I urge the government to extend its clean-up and restoration beyond buildings, temples and monuments and to draw up stringent environmental regulations. The valley's 3 million inhabitants matter, as well as its tourists.

Keshav Parajuly University of Southern Denmark, Odense, Denmark.

kepa@kbm.sdu.dk

\section{CONTRIBUTIONS}

See author guidelines for Correspondence submissions at http:// go.nature.com/cmchno 